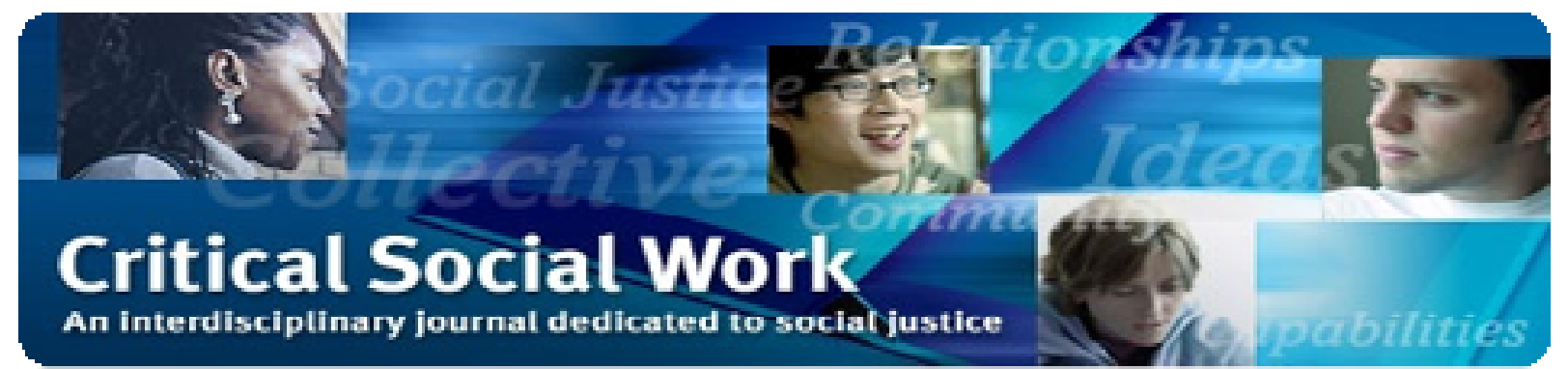

\title{
Critical Social Work
}

School of Social Work

University of Windsor

401 Sunset Avenue

Windsor, Ont.

Canada N9B 3P4

Email: cswedit@uwindsor.ca

Publication details, including instructions for authors and subscription information can be found at: http://uwindsor.ca/criticalsocialwork

Link to article:

http://www.uwindsor.ca/criticalsocialwork/an-exploration-of-elder-abuse-in-a-ruralcanadian-community

Critical Social Work, 2012 Vol. 13, No. 1 


\title{
An Exploration of Elder Abuse in a Rural Canadian Community
}

\author{
Critical Social Work 13(1) \\ Megan MacKay-Barr ${ }^{1}$ and Rick Csiernik ${ }^{2}$ \\ ${ }^{1}$ Windsor Regional Hospital Chatham Kent ACT Team, ${ }^{2}$ King's University College at The \\ University of Western Ontario
}

Acknowledgement: Funding for this study was secured through a New Horizons Grant. The authors would like to thank Milissa Wigfield for her assistance with the data tabulation.

\begin{abstract}
The Elder Abuse Awareness Committee of Chatham Kent, Ontario employed ten seniors (65 years of age or older) from this rural community to conduct an investigation of the knowledge and prevalence of elder abuse among their peers. The 236 study participants interviewed by the specifically trained elders were predominantly female ranging in age from 55 to over 90 . The majority were still living in their own homes, had completed high school or post-secondary education, and reported relatively good health. These attributes predicted a rate of disclosed elder abuse within the lower end of the four to ten percent range typically reported in the literature. However, an incidence rate of $19.1 \%$ was reported nearly double the upper end of the range, with 137 separate acts of verbal, emotional, and financial abuse reported by participants to their peers. Formal paid caregivers were identified as the most frequent perpetrators though two thirds of the incidents were not reported to anyone at the time they occurred primarily due to embarrassment, fear, being dependent upon the abuser, or simply not knowing who to tell about the abuse. In the minority of instances when the abuse was reported the most common sources informed were the police, a family physician, or a helping professional in the community.
\end{abstract}

KEYWORDS: Elder abuse, rural, Canada

\section{Introduction}

Elder abuse is both a social problem and a structural issue that has become more recognized, yet there remain few formal resources with which to provide help to those in need, particularly in rural Canada. This has become a growing area of concern given the rate at which the Canadian population is aging (Raina, Wolfson, Kirkland, Griffith, Oremus, et al, 2009). Elder abuse also reflects the fact that in Canada, and globally, older adults remain a marginalized and oppressed population (Lee \& Lee, 2011; Sherwin \& Winsby, 2011; Szanton, Gill, \& Thorpe, 2010; Walsh, Olson, Ploeg, Lohfeld, \& MacMillan, 2011). 
Chatham Kent is a rural region of south western Ontario, encompassing over 2,400 square kilometres (949 square miles) with a population of approximately 110,000. It is located within the Erie St. Clair Local Health Integration Network (LHIN), which is one of 14 LHINs that have been established in Ontario. LHINs are community-based, non-profit organizations funded by the Ontario Ministry of Health and Long-Term Care to plan, fund, and coordinate services delivered by hospitals, long-term care homes, community care access centers, community support service agencies, mental health and addiction agencies, and community health centers (Ontario's Local Health Integration Networks, 2006).

The Kent County Elder Abuse Awareness Committee is a voluntary group of service providers whose agencies have allowed them to serve on the committee because of the belief that elder abuse is a concern in the community and to their client group. The committee is comprised of representatives from the police, local hospital, long term care and residential homes, nursing agencies, public health, victim's services, the Woman's Centre, and the Alzheimer's Society. This committee meets monthly to discuss public education concerning elder abuse, to plan upcoming events, and to keep informed on elder abuse issues. This group provides no direct services, yet each of the members may deal with issues of elder abuse within their own role at their home agency. To obtain a better understanding of elder abuse among seniors in Chatham Kent the Committee sought and received funding to undertake a community- based study of the issue.

\section{Literature Review}

Elder abuse is an issue that many social workers and most other helping professionals encounter without having had the necessary training to respond to effectively. Wahl (2005) defined elder abuse as harm done to an older person that is violent or abusive and is often criminal in nature. It can entail both intentional actions that cause harm or create a serious risk of harm such as emotional abuse, exploitation, physical abuse, sexual abuse as well as the failure of a family or paid formal caregiver to provide an elder under their care with basic needs leading to neglect or abandonment (Jogerst, Daly, Brinig, Dawson, Schmuch, \& Ingram, 2003; Lachs \& Pillmer, 2004).

Emotional abuse, also referred to psychological abuse, includes threatening, intimidating, and belittling an older person. Name calling, swearing at, and treating the older adult as a child are also forms of emotional abuse (Callaghan, 1998). Exploitation is commonly associated with various forms of financial abuse including but not limited to the misuse or stealing of the older person's money or belongings. It can also include fraud, forgery or extortion, and the misuse of the authority granted by the older person through a Power of Attorney (Callaghan, 1998). Physical abuse is the hitting, slapping, pushing, or confining of older persons against their will (Callaghan, 1998). Sexual abuse, the act of any sexual contact without the consent of an older adult, is sometimes also included under the category of physical abuse (Callaghan, 1998).

According to Nerenberg (2000), another component of elder abuse is neglect, both wilful and passive. Wilful neglect occurs when a personal or paid caregivers purposefully withholds the necessities of life from their charges. These necessities can include, but are not limited to, food, medication, functional aides, appropriate shelter, clothing and contact with others. Passive 
abuse is when someone who is responsible for the care of an older person neglects to provide that care. This type of neglect can arise because caregivers do not understanding the scope of their roles or simply because they do not pay adequate attention to the needs of an older person. The argument that neglect needs to be wilful to be considered abuse has met much debate over the years. It is believed that untrained, over-burdened caregivers often provide inadequate care but it cannot be considered abuse because there is a lack of intent to harm. It is also argued that labelling these caregivers as abusers would be counter-productive and discourage them from seeking help with their responsibilities (Nerenberg, 2000).

A family member, a friend, an individual the older person relies upon for basic needs or staff in a group residential facility or in the older person's home can perpetrate elder abuse. A person that commits elder abuse usually has control or influence over the older person with those experiencing the abuse often knowing and trusting their abuser (Wahl, 2005). Thus, there are two basic principles associated with elder abuse. The first assumption is that some specific harm has occurred to a senior and the second is that it is as a result of the action by one or more persons in a position of trust, authority, or control (Lachs \& Pillmer, 2004).

International studies conducted in the United States and England reported elder abuse in the range of three to six percent (Cooper, Selwood, \& Livingston, 2008; Pillemer \& Finkelhor, 1988). In 1990, a National Survey of 2,000 older Canadian adults found that four percent of older adults disclosed experiencing some type of elder abuse (Health Canada, 1990); though, it is thought that this figure was low due to the reluctance of many to identify themselves as being a victim of abuse with actual rates being in the four to ten percent range (Public Health Agency of Canada, 1999). In 2005, there were 160 reported violent incidents for every 100,000 seniors in Canada. Senior males were 1.5 times more likely than senior females to be victims of violent crime. However, in terms of family violence rates were higher for women. There were 47 per 100,000 females over 65 who were violently victimized by a family member, compared to 36 per 100,000 males over 65 . Rates of family violence against seniors were highest when the accused was an adult child (15 per 100,000) or a current or former spouse (13 per 100,000). Interestingly, oldest seniors were less likely to be victims of family violence with those aged 85 having an incidence rate of 22 per 100,000, compared to 34 for seniors between 75 and 84 years of age, and 52 for the youngest seniors aged 65 to 74 years of age (Statistics Canada, 2007).

Trevitt and Gallagher (1996) found that there are many reasons why elder abuse is not reported including that victims, as part of the abuse, are isolated from family, friends and service providers by the abuser or that the abuser is a family member, friend or direct service provider themselves. They further found that there are also distinct cultural and economic factors that further hinder reporting. Often the abused person is fearful of telling anyone about the abuse because it could become worse, because the abuser may no longer provide any type of care, or that it would bring dishonour to their family in the eyes of their cultural community as well as the larger community. As well, many seniors who fall victim to elder abuse fear being removed from their homes and thus do not report the abuse to anyone (Trevitt \& Gallagher, 1996). Another reason for not reporting is the same as with other forms of abuse, elder abuse is viewed as being very painful and shameful for many abused persons and it is difficult to admit that someone they love would treat them in this manner (Callaghan 1998; Harden \& Khan-Hudson 2005). Service providers can also be reluctant to report suspected cases of abuse for fear of 
eroding client rapport and confidentiality (Anetzberger Palmisano et al., 2000). As well, when examining any type of abuse, the cultural context must be considered, as what one culture may define as abuse may be a viewed as being acceptable by another (Canadian Network for the Prevention of Elder Abuse (CNPEA), 2002 Canadian Policy Research Networks (CPRN), 2002; World Health Organization \& International Network for the Prevention of Elder Abuse (WHO \& INPEA), 2006).

While there had been a long held belief that the stress of care giving is one of the major causes of abuse of the elderly (Wieland, 2000), subsequent research has suggested that caregiver stress has no link to the occurrences of abuse. The British Geriatric Society (2003) conducted an inquiry into elder abuse and subsequently they identified five primary risk factors of abuse in the home:

I. Being socially Isolated, as those who are abused usually have fewer contacts than those who are not abused;

II. A history of a poor quality long-term relationship between the abused person and the abuser;

III. A pattern of family violence as a result of the abuser having previously been abused as a child;

IV. The dependence of the abuser on the abused for instrumental supports such as accommodation, financial, and/or emotional support; and,

V. When the abuser has a history of mental health problems; for example, suffering with a personality disorder or substance abuse problems.

Although most studies concur that gender and socioeconomic status are not linked to increasing the likelihood of abuse, in a global study conducted by WHO \& INPEA (2006), respondents agreed that women and individuals living in poverty are the ones most affected by elder abuse.

Presently, in the majority of Canada, there are no mandatory reporting laws regarding elder abuse. According to the Child and Family Services Act of Ontario (Government of Ontario, 1990), in the case of child abuse, any adult who suspects that a child is being abused is obligated to report their suspicions to either the police or their local Children's Aid Society. Additionally the act states that if individuals do not report suspected child abuse, they can be charged with a criminal offence. This reasoning makes sense when applied to children, as they are vulnerable and unable, in most cases, to protect themselves. However, the authors argue that elderly individuals are too a vulnerable population that often are unable to protect themselves from others who are intent on doing them harm. Older people can be isolated, infirm, and in the case of those with dementia, unable to seek resources or justice. In some cases, older persons can be just as vulnerable as children because their social contacts are often limited, they may suffer from poor health, and they rely on their caregiver for all of their basic needs. All too often, abused persons have no contact, except from their abuser, with the outside world. However, older people differ from children in that they usually have an income as well as assets. Their monetary value can be very attractive to a 'would-be' abuser; it can give an abuser motivation to control the older person on an ongoing basis. 
However, some people who work with senior populations, in either a direct service or protection capacity, believe that a mandatory elder abuse reporting law would add to further age discrimination. According to Neno and Neno (2005), "in the United States, mandatory reporting of suspected cases of abused older people has been adapted, but this has been criticized because it destroys confidentiality, differentiating older people from other adults" (p. 5). However, even if there were to be mandatory reporting laws for elder abuse implemented in Canada, a significant issue that would arise is that there are very few, if any, services to deal with these situations, whether they are reported or not. An elder abuse investigation can take a considerate amount of time to fully complete, with some cases requiring over two continuous weeks of worker time and effort (Neale, Hwalek, Goodrich, \& Quinn, 1996). However, in many urban and rural settings across Canada (Bobyk-Krumins \& Holosko, 2004; Macdonld, 2011; Skinner, Rosenberg, Lovell, Dunn, Everitt, Hanlon, \& Rathwell, 2008), including Chatham Kent, there is a significant gap in social services for seniors who are abused, as evident by the lack of any one person assigned from any organization to delve into cases of elder abuse .

Furthermore, a single elder abuse case can take a case worker upwards of 70 to 80 hours to complete, which suggests the need for social service interventions, programs, and case management. In addressing a significant community need such as this, it is prudent to understand the entire context of the situation and thus begin the process with a community-based assessment.

\section{Methodology}

\section{Design}

The study collected data using a traditional single-group, one time, cross-sectional administration of a questionnaire that was created by the Kent County Elder Abuse Awareness Committee. The survey consisted of 80 questions, which include items taken from previously successfully conducted studies from three other rural Ontario regions: Essex, Wellington/Dufferin and Grey/Bruce. While basic demographic information were collected, the primary focus of the survey was to discover what older adults knew about elder abuse, what they would do, if anything, should they or someone they cared about were abused, and if they themselves had ever been victims of elder abuse. The survey also covered what types of services they had used if they had been a victim of elder abuse. During the project's development phase, the planning committee consulted with seniors from the community, in an effort to ensure their perspective was represented from the onset of the study's design.

\section{Data Collection}

In an attempt to better engage this population and obtain responses that were more forthright, 10 retired seniors were trained to conduct the interviews. The recruitment process for research assistants' targeted, but was not limited to, retired community nurses, social workers, and teachers, as they would have the most experience in visiting others in their homes and in asking questions in a structured manner, which is a task that not everyone is comfortable completing. The Interviewers were trained to conduct the interviews in a similar manner. Along with interviewing skills, the training also included information regarding elder abuse and the 
services available in the community, in the event that any of the participants disclosed abuse during an interview. The interviewing team included seniors from different areas of the county. Each individual was to interview a minimum of 20 persons over the age of 55 within their designated geographic area. By using this convenience sampling approach, the committee was able to have representation from various areas of Chatham Kent. Interviewers were instructed to contact individuals in a range of settings including seniors' centres, retirement homes, senior's apartment buildings, and neighbourhoods where there is a high concentration of older adults residing. This process actually led to a larger than anticipated response rate, with each interviewer, on average, completing slightly more than 23 interviews. Each senior who participated in the study was provided with an honorarium of a five-dollar gift certificate from an area coffee shop, while each interviewer was paid \$20 for each completed interview.

Each interviewer signed a document of confidentiality prior to being hired and they maintained confidentiality throughout the project by not recording the participants name or address on each of the surveys. . Seniors living in nursing homes were purposely omitted from the sample, as the Kent County Elder Abuse Awareness Committee believed that it would be impossible to obtain informed consent from many of the nursing home residents to complete the survey. Although just as significant, elder abuse perpetrated by paid caregivers in a Long Term Care Home is different than abuse perpetrated in the home by family or informal caregivers. In the case of the paid caregiver in a nursing home, the causes of abuse is often due to poor working conditions, a lack of adequate staffing, disgruntled workers, employees who lack in education, and/or poor work-related training for employees (Hardin \& Khan-Hudson, 2005). The Ontario Ministry of Health and Long-Term Care has established a toll-free telephone line, which is posted in all Ministry funded long-term care homes, with the aim of giving anyone who witnesses abuse someone to call and report their concerns. As a result, the Ministry has put into place a system with which to investigate and prosecute the crimes that happen within nursing home facilities. For these reasons, this sub-group was not examined within the scope of this study.

\section{Data Analysis}

Descriptive statistical analysis of the data was completed using SPSS version 15 for Windows.

\section{Results}

\section{Demographics}

There were 236 completed surveys representing all areas of Kent County. In total, 175 $(74.2 \%)$ women and $61(25.8 \%)$ men completed the survey, with nearly one-third of the respondents falling between the ages of 60-69 and nearly another third falling in the age range of 70-79 years. Finally, one quarter of the respondents were 80 years of age or older (see Table 1). 
Table 1

Respondent Age

\begin{tabular}{|l|c|c|}
\hline \multicolumn{1}{|c|}{ Age } & $\mathrm{N}$ & $\%$ \\
\hline $55-59$ & 19 & $8.1 \%$ \\
\hline $60-69$ & 74 & $31.4 \%$ \\
\hline $70-79$ & 76 & $32.2 \%$ \\
\hline $80-89$ & 51 & $21.6 \%$ \\
\hline over 89 & 8 & $3.4 \%$ \\
\hline no response & 8 & $3.4 \%$ \\
\hline
\end{tabular}

The majority of the study's participants were married $(n=105 ; 44.5 \%)$ with the next largest group being widowed $(n=82$; approximately $36.3 \%$ of participants). Only 16 participants $(7.5 \%)$ had never married, while $23(9.7 \%)$ were divorced. Most of the participants lived in a single-family home $(\mathrm{n}=148 ; 62.7 \%)$, while a much smaller proportion of participants resided in an apartment $(\mathrm{n}=35 ; 14.8 \%)$, a condominium $(\mathrm{n}=17 ; 7.2 \%)$, or a mobile home $(\mathrm{n}=$ 13; 5.5\%). All but two of the participants spoke English, Twelve participants self-identified as being members of a visible minority. One-third of the study's participants had some postsecondary education, with $43.2 \%$ reporting high school as their highest level of education. This was also a relatively healthy group; only $3.0 \%$ of participants indicated that their health was poor, $8.2 \%$ listed their health as fair, while the remainder reported that their health was okay $(22.9 \%)$, good $(54.5 \%)$, or excellent $(13.4 \%)$.

\section{Issues Relating to Elder Abuse}

It is interesting and important to note that the vast majority of the study participants $(83.5 \%)$ did not feel that they had been discriminated against because of their age. When asked the question "do you feel that elder abuse is a problem in Chatham Kent?" Eighty-three (35.2\%) said yes, $19(8.1 \%)$ said no, with over one half $(n=125 ; 53.0 \%)$ being unsure if this was an issue in their community. However, nearly one in five of the participants $(n=45 ; 19.7 \%)$ disclosed that they had experienced elder abuse themselves. The most common forms of abuse were being sworn at or insulted, threats of violence, and having important information withheld from them. In total, 45 respondents indicated 112 distinct incidents abuse of which only $34(30.4 \%)$ were reported. Most reported was s disclosure of important information pertaining to them (45.4\%) with the actual theft of money reported only once (5.6\%) in eighteen occurrences. The most common person to perpetrate the abuse was a spouse or a formal paid caregiver (see Table 2). 
MacKay-Barr \& Csiernik

Table 2

Frequency of abuse and perpetrator $(n=236)$

\begin{tabular}{|l|l|l|l|l|l|l|l|}
\hline & frequency & reported & $\begin{array}{l}\text { paid } \\
\text { caregiver }\end{array}$ & child & spouse & $\begin{array}{l}\text { Other } \\
\text { family } \\
\text { or } \\
\text { friend }\end{array}$ & Other \\
\hline $\begin{array}{l}\text { Threatening } \\
\text { violence }\end{array}$ & 24 & 8 & 13 & 4 & 9 & 5 & 0 \\
\hline Sworn at, insulted & 31 & 12 & 6 & 6 & 14 & 3 & 4 \\
\hline Frightening you & 17 & 3 & 8 & 5 & 7 & 2 & 2 \\
\hline $\begin{array}{l}\text { Withholding } \\
\text { important } \\
\text { information }\end{array}$ & 22 & 10 & 5 & 4 & 4 & 5 & 3 \\
\hline $\begin{array}{l}\text { Stealing } \\
\text { money/possessions }\end{array}$ & 18 & 1 & 3 & 6 & 0 & 5 & 4 \\
\hline
\end{tabular}

For those who had previously disclosed their experience of abuse it was most often to a friend rather than to a family member or partner (see Table 3 ).

Table 3

Who did you first tell about your abuse?

\begin{tabular}{|l|c|c|c|c|c|}
\hline & Frequency & Child & Spouse & Family/Friend & Other \\
\hline Threatening Violence & 24 & 2 & & 2 & 4 \\
\hline Sworn at, insulted & 31 & 1 & 1 & 6 & 4 \\
\hline Frightening You & 17 & & & & \\
\hline $\begin{array}{l}\text { Withholding Important } \\
\text { Information }\end{array}$ & 22 & & & & 4 \\
\hline Stealing Money/Possessions & 18 & 3 & & 7 & 1 \\
\hline
\end{tabular}

Although only a minority of those who had experienced abuse sought assistance from a professional service, those most often contacted were the police, one's family doctor, the Community Care Access Centre, or a counsellor in the community (see Table 4). 
MacKay-Barr \& Csiernik

Table 4

From whom did you seek assistance?

\begin{tabular}{|l|l|l|l|l|l|l|}
\hline & Frequency & doctor & police & CCAC & counsellor & other \\
\hline Sworn at, insulted & 31 & 3 & 2 & 1 & 3 & \\
\hline Frightening you & 17 & 2 & 1 & 1 & & 2 \\
\hline $\begin{array}{l}\text { Withholding } \\
\text { important } \\
\text { information }\end{array}$ & 22 & 1 & 1 & 1 & 1 & 3 \\
\hline $\begin{array}{l}\text { Stealing } \\
\text { money/possessions }\end{array}$ & 18 & 2 & 3 & 2 & 1 & 2 \\
\hline
\end{tabular}

The reasons most often cited for not reporting the abuse was being too embarrassed about the abuse, being afraid that the abuser would find out and the abuse would increase, being dependent upon the abuser for help with activities of daily living, and not having any idea who to tell about their problem (see Table 5).

Table 5

Reasons for not reporting by type of abuse

\begin{tabular}{|c|c|c|c|c|c|c|}
\hline 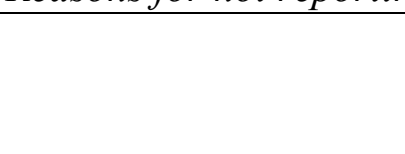 & Frequency & Embarrassment & Fear & Dependence & $\begin{array}{l}\text { Didn't } \\
\text { know who } \\
\text { to tell }\end{array}$ & Other \\
\hline Sworn at, insulted & 31 & 9 & 3 & 3 & 4 & \\
\hline Failure to repay loans & 25 & 3 & 1 & & 1 & 3 \\
\hline Threatening Violence & 24 & 7 & 3 & 2 & 1 & \\
\hline $\begin{array}{l}\text { Withholding important } \\
\text { information }\end{array}$ & 22 & 7 & 3 & 3 & & \\
\hline $\begin{array}{l}\text { Stealing } \\
\text { money/possessions }\end{array}$ & 18 & 5 & 1 & 1 & 1 & \\
\hline
\end{tabular}

\section{Discussion}

The results of this community-based survey, which explored elder abuse and conducted by trained seniors, indicates a greater number of individuals having experienced elder abuse than typical estimates. Rather than being in the anticipated four to ten percent range, results found a rate nearly double (19.1\%) the upper estimate. One contributing factor to a higher rate may be a function of who the interviewers were. Survey participants were far more likely to disclose abuse to their friends than to any other group. In this study, the interviewers represented peers to the participants, whereas in most elder abuse research interviewers are far younger than those being interviewed. What makes this result even more surprising is that survey respondents were overall healthy, with relatively low care needs, affluent, and well educated, which is in contrast to the literature, which speculates that people who are in need of physical care and are of lower socioeconomic status are often at greater risk of abuse (Litwin \& Zoabi, 2004).

It is also notable that even though almost half of the participants claimed that they would know where to seek assistance in case of abuse, only a fraction reported the abuse or sought any assistance. In cases when self-disclosure did occur, it was far more likely to be to a friend than 
to a family member. This further supports the need to inform all seniors about this social issue, not only so that individuals know what to do, but how they can, more readily assist their peers. If this group of well educated, active, and connected seniors do not feel able to report or seek assistance for the abuse that they have suffered, it would follow that a more vulnerable population would have even greater issues. This can have profound implications for older adults who because of cultural, language, and economic issues are even further isolated.

The difficulty in conducting elder abuse research is that those who are at the greatest risk and suffering the greatest amount of abuse are often the most isolated and thus vulnerable. It is a rare occurrence that this group of seniors are available to tell their story because the abuser will often keep them away from the outside world (Comijs, Smit, Pot, Bouter \& Jonker, 1998; Walsh, Olson, Ploeg, Lohfeld, \& MacMillan, 2011). Even if members of this even more vulnerable group had the opportunity to participate in this type of survey, there is a likelihood that they would be reluctant to report their actual circumstances for fear their abuser would retaliate or abandon them (Callaghan, 1998). Language was a potential limitation of this study because in order for seniors to participate, they had to be able to read and write English, as the survey was not given in any other language.

As with any community-based study, this research has a number of limitations that preclude it from being generalizable. As mentioned above, the sample was made up of a healthy group of seniors, while the literature states that the frail elderly, that is those with dementia and high care needs, are at the highest risk of elder abuse (Chez, 1999). Thus, the data collection process limited accessing more isolated and socially vulnerable members of this population. In addition, it was a relatively young sample, with those over the age 89 accounting for only eight percent of the participants. Those in this very old age group may have greater health needs and too perhaps may be at greater risk for abuse.

The Elder Abuse Awareness Committee of Chatham Kent functions under this multidisciplinary model with various service providers from social service agencies, the police, victim's service, the hospital, and long term care. This is a model that is supported in the literature, which states that interdisciplinary response services should include representation from the medical, legal, and police community, as well as social services and mental health, housing, and long term care (Wolf \& Li, 1999). Unfortunately, all of the committee member's involvement in Chatham Kent is provided on a voluntary basis, with no one person or agency designated to facilitate the group or make elder abuse their primary focus. With caseloads high and demands on time substantive, extra work outside one's role is difficult to include. A needed response to enhance practice with this population arising from the research findings would be to have a dedicated coordinator for elder abuse services, not only to organize the committee but also to provide regular education and respond to situations of abuse, which are highlighted in the findings, by linking those affected with appropriate services. An elder abuse response coordinator could also connect community resources to develop comprehensive and integrated care plans, promote coordination between agencies, and advocate for the need for designated elder abuse services. Further, Neno and Neno (2005) found that a help line, which is open to professionals and the public and offers education and guidance, was a successful method to facilitate elder abuse reporting. The ability to report abuse or ask for help in an anonymous basis 
was a key contributor to this approach and could be easily included within a regional coordinated service.

Elder abuse cannot be dismissed as just another type of domestic violence. Arrest, removal and other policies have a different impact on the elderly person then they do on the child or spouse abuse victim (Callaghan, 1998, p. viii).

It is become recognized in the literature, in practice and slowly in the larger community that providing service for elder abuse is very difficult. A substantive issue are the personal histories of those who suffer the abuse and the larger structural issues that surround aging and resource allocation for seniors that further inhibit disclosure. Payne (2002) stated that "elder abuse is perhaps one of the most difficult types of family violence to study" (p 622). Presently, two primary models of service delivery have been developed across North America to respond to elder abuse. Firstly, a protective service approach, which is based upon the child abuse reporting model and secondly, a response system and domestic violence model, which emphasizes victim empowerment (Nerenberg, 2000).

These two options then left us with several additional questions. Is it time to mandate reporting of elder abuse as we mandated the reporting of child abuse, despite the concerns raised by those who follow a victim empowerment model and therefore feel mandated reporting undermines client self-determination? In child welfare, elaborate systems have been instituted to assess risk and determine safety. Which led us to ask, do we need to be considering similar courses of action for another vulnerable population, such as seniors, or do we maintain the current voluntary system, which appears to be missing large segments of vulnerable individuals? What are the implications for newcomer groups who have very different relationships with their older adult population? As well, what training and education should be part of core curriculum for helping professionals, knowing that this is a growing population not only in Chatham Kent but across Canada? Likewise, what types of community education campaigns are necessary to further highlight this important social issue?

This study investigated the prevalence of elder abuse in a community-based sample of seniors living independently in the Municipality of Chatham Kent, Ontario. It supports the view that older adults in Canada are a marginalized and oppressed population. It is important to do this type of community based research to better understand the needs of this population and to provide services based upon those needs, partially because their marginalization leads to limited attention in the realms of research, practice, and policy. The findings indicate that elder abuse appears to be a significant issue in this community and that it may be at an even higher level than what is thought to be across Canada. With this knowledge, it is the hope of the Chatham Kent Elder Abuse Awareness Committee that the data collected can be used to increase public awareness of this problem. It is also hoped that the results of the study will influence policy makers to view that specific elder abuse services are necessary in this community, both in rural and in urban Canada. For social workers it also indicates that not only education and awareness within this population is needed but in fact greater advocacy to address the oppression and harm faced by this group particularly in light of the fact that Canada has an aging population and thus the risk for even greater rates of prevalence of these issues exists. 
MacKay-Barr \& Csiernik

\section{References}

Anetzberger, G., Palmisano, B., Sanders, M., Bass, B., Dayton, C., Eckert, S., \& Schimer, M. (2000). A model for elder abuse and dementia. The Gerontologist, 40 (4), 492-497.

British Geriatric Society. (2003). Written evidence submitted for the House of Commons Health Select Committee Inquiry into Elder Abuse. (Evidence No. 177). London, UK: Author.

Bobyk-Krumins, J., \& Holosko, M. (2004). Abuse and neglect of the elderly person. In M. Holosko \& M. Feit. (Eds.), Social work practice with the elderly ( ${ }^{\text {rd }}$ ed.). Toronto, ON: Canadian Scholar's Press.

Canadian Network for the Prevention of Elder Abuse. (2005). What is senior abuse? Retrieved from http://www.cnpea.ca/what_is_abuse.htm

Canadian Policy Research Networks. (2002). Asking Canadian NGOs what matters on aging. Retrieved from http:// www.cprn.com/en/doc.cfm?doc $=93$

Canadian Policy Research Networks. (2002). Time for action on unpaid care giving: research points the way. Retrieved fromhttp://www.cprn.org/en/doc.cfm?doc=1366

Callaghan J. (1998). Elder abuse and one community's response. International Journal of Health Care Quality Assurance Incorporating Leadership in Health Services, 11(2), 6-10.

Chez, R. (1999). Elder abuse the continuum of family violence. Preventive Care Update, 6(4), 132-134.

Comijs, C., Smit, J., Pot, A., Bouter, L., \& Jonker, C. (1998). Risk indicators of elder mistreatment in the community. Journal of Elder Abuse and Neglect, 9(4), 67-76.

Cooper, C., Selwood, A., \& Livingston, G. (2008). The prevalence of elder abuse and neglect: A systemic review. Age and Ageing, 37(2), 151-160.

Government of Ontario. (1990). Child and Family Services Act. Retrieved from http://www.elaws.gov.on.ca/html/statutes/english/elaws_statutes_90c11_e.htm

Hardin, E. \& Kahn-Hudson, A. (2005). Elder abuse-“society’s dilemma”. Journal of the National Medical Association, 97(1), 91-94.

Health Canada. (1990). Elder abuse. Retrieved from: http://www.phac-aspc.gc.ca/ncfvcnivf/familyviolence/pdfs/elderab.pdf

Jogerst, G., Daly, J., Brinig, F., Dawson, J., Schmuch, A., \& Ingram, J. (2003). Domestic elder abuse and the law. American Journal of Public Health, 93(12), 2131-2136.

Lachs, M., \& Pillmer, K. (2004). Elder abuse. Lancet, 364 (9441), 1263-1272. 
MacKay-Barr \& Csiernik

Lee, E., \& Lee, J. (2011). Gender differences in predictors of mental health among older adults in South Korea. The International Journal of Aging and Human Development, 72(3), 207-223.

Litwin, H., \& Zoabi, S. (2004). A multivariate examination of explanations for the occurrence of elder abuse. Social Work Research, 28(3), 133-143.

McDonald, L. (2011). Elder abuse and neglect in Canada: the glass is still half full. Canadian Journal of Aging, 30(3), 437-465.

Neal, A., Hwalek, M., Goodrich, C., \& Quinn, K. (1996). The Illinois Elder Abuse system: Program description and administrative findings. The Gerontologist, 36(4), 502-511.

Neno, R., \& Neno, M. (2005). Identifying abuse in older people. Nursing Standard Harrow-onthe-Hill, 20(3), 43-47.

Nerenberg, L. (2000). Developing a response to elder abuse. Generations, 24(2), 86-93.

Ontario's Local Health Integration Networks. (2006). About LHINs. Retrieved from http://www.lhins.on.ca/aboutlhin.aspx?ekmensel=e2f22c9a_72_184_btnlik

Payne, B. (2002). An integrated understanding of elder abuse and neglect. Journal of Criminal Justice, 30(6), 535- 547.

Pillemer, K., \& Finkelhor, D. (1988). The prevalence of elder abuse: A random sample survey. The Gerontologist, 28(1), 51-57.

Public Health Agency of Canada. (1999). Abuse and neglect of older adults. Retrieved from http://www.phac-aspc.gc.ca/ncfv-cnivf/familyviolence/html/agenegl_e.html.

Raina, P., Wolfson, C., Kirkland, S., Griffith, L., Oremus, M., Patterson, C., Tuokko, H., Penning, M., Balion, C., Hogan, D., Wister, A., Payette, H., Shannon, H., \& Brazil, K. (2009). The Canadian Longitudinal Study on Aging (CLSA). Canadian Journal on Aging, 28(3), 221-229.

Sherwin, S., \& Winsby, M. (2011). A relational perspective on autonomy for older adults residing in nursing homes. Health Expectations, 14(2), 182-190.

Skinner, M., Rosenberg, M., Lovell, S., Dunn, J., Everitt, J., Hanlon, N., \& Rathwell, T.(2008). Services for seniors in small-town Canada: The Paradox of community. Canadian Journal of Nursing Research, 40(1), 80-101.

Statistics Canada. (2007). Family violence in Canada, 2007. Retrieved from http://www.statcan.ca/english/freepub/85-224-XIE/85-224-XIE2007000.pdf 
MacKay-Barr \& Csiernik

Szanton, S., Gill, J., \& Thorpe, R. (2010). The society-to-cells model of resilience in older adults. Annual Review of Gerontology and Geriatrics, 30(1), 5-34.

Trevitt, C., \& Gallagher, E. (1996). Elder abuse in Canada and Australia: Implications for nurses. International Journal of Nursing Studies, 33(6), 651-659.

Wahl, J., \& Purdy, S. (2005). Elder abuse: The hidden crime. Toronto, ON: Advocacy Centre for the Elderly and Community Legal Education Ontario.

Walsh, C., Olson, J., Ploeg, J., Lohfeld, L., \& MacMillan, H. (2011). Elder abuse and oppression: Voices of marginalized elders. Journal of Elder Abuse and Neglect, 23(1), $17-42$.

Wieland, D. (2000). Abuse of older persons: An overview. Holistic Nursing Practice, 14(4), 4050 .

Wolf, R., \& Li, D. (1999). Factors affecting the rate of elder abuse reporting to a state protective services program. The Gerontologist, 39(2), 222-228.

World Health Organization \& International Network for the Prevention of Elder Abuse. (2006). Missing voices: views of older persons on elder abuse. Retrieved from http://whqlibdoc.who.int/hq/2002/WHO_NMH_VIP_02.1.pdf 